\title{
Chemical composition, antibacterial, antifungal and antioxidant activities of Taxus baccata essential oil from Algeria
}

\author{
KHAOULA BENLEMBAREK ${ }^{1}$, TAKIA LOGRADA ${ }^{1}$, MESSAOUD RAMDANI ${ }^{1, \boldsymbol{v}}$, GILLES FIGUEREDO ${ }^{2}$, \\ PIERRE CHALARD ${ }^{3}$ \\ ${ }^{1}$ Laboratory of Natural Resource Valorization, Faculty of Life and Natural Sciences, Ferhat Abbas University. Setif-1. 19000 Setif, Algeria. \\ Tel./fax.: +213658 101010, `email: ramdanimessaoud@yahoo.com \\ ${ }^{2}$ LEXVA Analytique. 460 Rue Du Montant, 63110 Beaumont, France \\ ${ }^{3}$ Université Clermont Auvergne. CNRS, SIGMA Clermont, ICCF, F-63000 Clermont-Ferrand, France
}

Manuscript received: 24 October 2021. Revision accepted: 24 November 2021.

\begin{abstract}
Benlembarek K, Lograda T, Ramdani M, Figueredo G, Chalard P. 2021. Chemical composition, antibacterial, antifungal and antioxidant activities of Taxus baccata essential oil from Algeria. Biodiversitas 22: 5475-5483. This work aims to study the chemical composition, the antibacterial, antifungal and antioxidant activities of Taxus baccata essential oil of Algeria. The essential oil was obtained by hydro distillation; its chemical composition was determined by GC and GC-MS analysis. The antibacterial and antifungal activities are evaluated by the disk diffusion method against three-gram negative bacteria, four-gram positive bacteria and four phytopathogenic fungi. The evaluation of antioxidant activity is carried out by the DPPH scavenging method. Twenty-seven compounds have been identified in the essential oil, where the major product was undecanone-2, followed by nonanone- 2 , tridecanone-2, decanone2 and the methyl dehydroabietic. The T. baccata essential oil showed moderate antibacterial and antifungal activities against the strains tested, with the exception of E. faecalis, MRSA and Fusarium graminum, which have shown significant resistance. T. baccata essential oil has a moderate antioxidant activity.
\end{abstract}

Keywords: Algeria, biological activities, chemical composition, essential oil, Taxus baccata

\section{INTRODUCTION}

The genus Taxus, family of Taxaceae, contains about twenty species (Wahab et al. 2016). The majority of plants in the genus Taxus are endangered evergreen trees or shrubs that often grow slowly (Liu et al. 2016). In Algeria, Taxus is represented by only one species Taxus baccata L., known as the common yew (Quezel and Santa 1962). Taxus baccata is a dioecious tree ranging from small to medium-size, distributed in Europe, Asia and Africa (Dizdarević et al. 2019). The leaves of T. baccata are linear, scattered and spread in two opposite rows. The fruit is fleshy-succulent, reddish with a bony ovoid seed (Quezel and Santa 1962).

Taxus baccata is considered a valuable woody species with a significant medicinal value due to the presence of paclitaxel (Taxol), which is found in the leaves and considered one of the most promising natural anticancer agents (Jiang et al. 2011; Fenjuan et al. 2021).

The chemical composition of T. baccata has not been much studied. In Serbia, essential oils from needles are rich in oct-1-en-3-ol, (3Z)-hex-3-en-1-ol and myrtenol (Stefanović et al. 2016). Radulovic et al. (2011) in a study on aerial parts of T. baccata, showed that the essential oil is rich in hexahydrofarnesyl acetone, myrtenol, (Z)-3hexenol, 3-methyl-2-butenoic acid and tricosan. The oils from the fresh leaves of $T$. baccata collected from the Aegean and Mediterranean region of Turkey are dominated by 1-octen-3-ol, (E)-2-hexen-1-ol, caryophyllene oxide, hexahydrofarnesyl acetone and 1-hexanol (Yasar 2013). The essential oils of $T$. wallichiana leaves contain 3-hexen1-ol, 2-hexenal, 1-octen-3-ol, 3-octanone and hexadecanoic acid as the main products (Jian-chun et al. 2012).

The composition of $T$. chinensis essential oils in Vietnam has shown the dominance of $\alpha$-pinene and caryophyllene oxide (Houng et al. 2020). The study by Zhao et al. (2016) showed that the cis-vaccenic acid and (E)-palmitoleic acid are major components in the $T$. chinensis essential oil, on the other hand, the Chinese populations of $T$. chinensis are rich in n-hexadecanoic acid and in Phthalic acid mono-2-ethylhexyl ester (Wei and Yin 2019).

The leaves extract of $T$. baccata from India, tested against Escherichia coli, Yersinia pestis, Pseudomonas aeruginosa, Bacillus cereus, Listeria monocytogenes and Staphylococcus aureus showed moderate antibacterial activity (Prakash et al. 2018). In Ukrania, alcoholic extracts of $T$. baccata have low antimicrobial activity against Listeria monocytogenes, Corynebacterium xerosis and Candida albicans (Zazharskyi et al. 2019). Ethanolic extracts from the leaves of $T$. baccata has given a broadspectrum antibacterial activity against multi-resistant bacterial strains (MDR) (Bernaitis et al. 2013). The essential oil from the leaves of $T$. cuspidata showed moderate antimicrobial action against Bacillus cereus, Staphylococcus aureus, Listeria monocytogenes, Salmonella typhimurium and Escherichia coli (Bajpai et al. 2013). 
Extracts of various species of the genus Taxus possess an important antifungal activity. Methanolic extracts of $T$. baccata has a potential antifungal activity against $A$. brasiliensis and C. albicans (Dizdarević et al. 2019). Methanolic extracts from the leaves of T. baccata from Iran were very effective against Candida albicans (Fazeli-Nasab et al. 2021). Biflavones isolated from T. baccata, tested against three fungi showed significant activity (Baranowska and Wiwart 2003). Taxoids extracted from the leaves of $T$. cuspidata have moderate antifungal activity against phytopathogenic fungi (Tachibana et al. 2005).

The antioxidant activity is due to the richness of $T$. baccata in polyphenolic compounds (Milutinovic et al. 2015). In Algeria, Bekhouche et al. (2021) showed that the methanolic extract of $T$. baccata needles exhibits a greater antioxidant activity more than the synthetic antioxidant BHT. The essential oil from the stems of T. cuspidata has shown a strong antioxidant capacity against the DPPH radical (Bajapai and Baek 2016). In India, the study of the antioxidant activity of $T$. wallichiana raw extracts from the leaves, showed a very remarkable antioxidant activity (Ganie et al. 2015)

This study aims to identify the chemical composition of the Algerian Taxus baccata essential oil and to study its antibacterial, antifungal and antioxidant activity.

\section{MATERIALS AND METHODS}

\section{Plant material}

Taxus baccata was collected during October 2020 from the Babor forest in Algeria (Figure 1). The population of $T$. baccata is found at an altitude of $1940 \mathrm{~m}$ with geographic coordinates of $36^{\circ} 30^{\prime} 08^{\prime \prime} \mathrm{N}$ and $5^{\circ} 27^{\prime} 17^{\prime \prime} \mathrm{E}$.

\section{The essential oils extraction}

The aerial parts (100 $\mathrm{g}$ of dried stems and leaves), were hydro distilled for $3 \mathrm{~h}$ using a Clevenger-type apparatus according to the method recommended by the European Pharmacopeia. Voucher specimens were deposited in the herbarium of the Department of Biology and Ecology, Setif-1 University, Algeria. The distilled essential oil was dried over anhydrous sodium sulfate filtered and stored in sealed vials at $4-5^{\circ} \mathrm{C}$, prior to further analyses. The Essential oil yield was calculated by the following formula:

$$
\text { Essential oil yield }=\frac{\text { Essential oil mass }}{\text { plant matter mass }} \times 100
$$

\section{Essential oils analysis}

The essential oils were analyzed using a Hewlett Packard gas chromatograph (CG/FID 7890), coupled to a gas chromatograph (CG/MS 7890/5975C), equipped with a Column A-polar: DB5 MS: $40 \mathrm{~m} 0.18 \mathrm{~mm} 0.18 \mu \mathrm{m}$, programmed from $50^{\circ} \mathrm{C}$ for $5 \mathrm{~min}$ at rate of $5^{\circ} \mathrm{C} / \mathrm{min}$ up to $300^{\circ} \mathrm{C}$. Helium was used as the carrier gas $(1.0 \mathrm{~mL} / \mathrm{min})$; injected in the split mode (1:30), injector and detector temperature of $280^{\circ} \mathrm{C}$ with split $1 / 100$. The mass spectrometer worked in the EI mode at $70 \mathrm{eV}$; electron multiplier, $2500 \mathrm{~V}$; ion source temperature, $180^{\circ} \mathrm{C}$; the $\mathrm{MS}$ data were acquired in the scan mode in the $\mathrm{m} / \mathrm{z}$ range of 33450. The identification of the components was based on the comparison of their mass spectra with those of NIST mass spectral library (Masada 1976; NIST 2002) and those described by Adams, and the comparison of their retention indices either with those of authentic compounds or with literature values (Adams 2007).

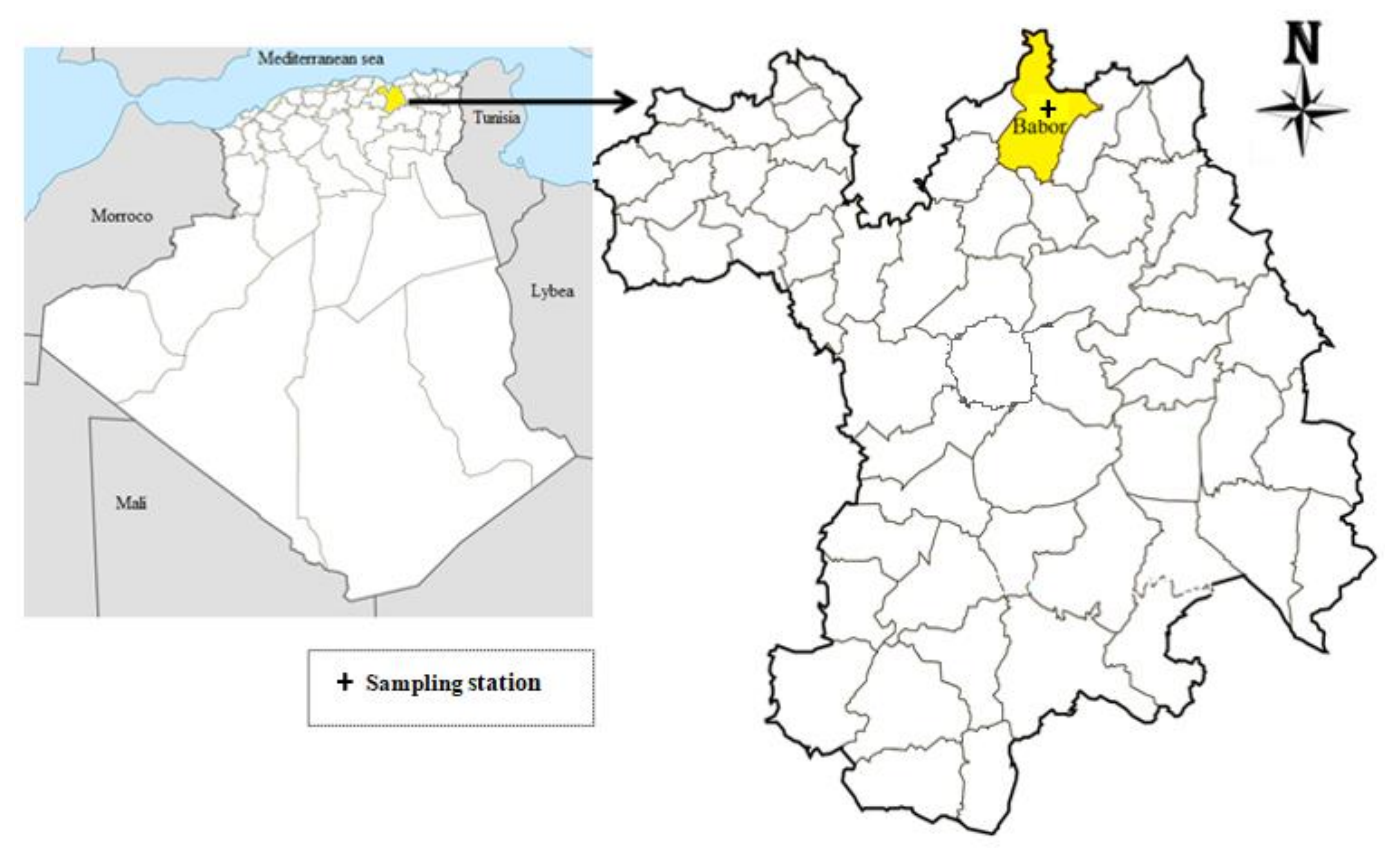

Figure 1. Taxus baccata sampling station in Babor forest, Setif Province, Algeria 


\section{Antibacterial activity assessment}

The in-vitro evaluation of antimicrobial activity of Taxus baccata essential oils was performed by the disc diffusion method. Bacterial species were tested individually with the essential oil including three Gramnegative bacteria (Escherichia coli ATCC 25922, Proteus mirabilis ATCC 35659 and Pseudomonas aeruginosa ATCC 27853), and four Gram-positive bacteria (Staphylococcus aureus ATCC 25923, Enterococcus faecalis ATCC 51299, Bacillus cereus ATCC 11778 and MRSA ATCC 43300). These bacteria were obtained from the Pasteur Institute of Algiers and M'sila, the applied microbiology laboratory of Setif University and Setif Hospital. The bacterial inoculums were prepared from overnight broth culture in physiological saline $(0.8 \% \mathrm{NaCl})$ to obtain an optical density ranging from 0.08 to 0.1 at 625 nm. Mueller Hinton agar (MHA) was poured in Petri dishes, solidified, and surface dried before bacteria inoculation. Sterile discs (6 mm) were placed on inoculated MHA, filled with $10 \mu \mathrm{l}$ of stock solution of essential oils $(1 / 1 \mathrm{v} / \mathrm{v})$ or diluted essential oils $(1 / 2$ and $1 / 3 \mathrm{v}$ : $\mathrm{v}$ of DMSO). DMSO was used as a negative control and the antibiotics Colistin, Cefotaxime, Gentamicin and Imipenem were used as positive control. The bacterial growth inhibition was determined as the diameter of the inhibition zones around the discs. The Petri dishes were incubated at $37^{\circ} \mathrm{C}$ for 18 to $24 \mathrm{~h}$ aerobically. All the tests were performed in triplicate, and the means were calculated as results. The sensitivity to essential oils was classified by diameter of inhibition halos as follows: not sensitive (-) for diameter less than $8 \mathrm{~mm}$; sensitive $(+)$ for diameter 9-14 $\mathrm{mm}$; very sensitive (++) for diameter $1519 \mathrm{~mm}$ and extremely sensitive $(+++)$ for diameter larger than $20 \mathrm{~mm}$ (Ponce et al. 2003).

\section{Antifungal activity assessment}

The evaluation of the antifungal activity of $T$. baccata essential oil is carried out in vitro by the technique of diffusion on discs. Four phytopathogenic fungal strains of clinical origin, obtained from the Laboratory of Applied Microbiology (Faculty of Nature and Life Sciences, Ferhat Abbas University of Setif) were used Alternaria alternata, Fusarium oxysporum, Fusarium graminum and Puccinia sp. Agar disc of the fungal culture is applied to the Petri dish based on Sabouraud Dextrose Agar (SDA) culture media. Sterile discs of $6 \mathrm{~mm}$ in diameter are placed on the agar surface, after having been loaded with $10 \mu \mathrm{L}$ of pure essential oil (1/1v) or essential oil diluted with DMSO (1 / $2 \mathrm{v}, 1 / 3 \mathrm{v})$. A negative control consisted of fungal agar disks in the absence of essential oil was conducted. Incubation was performed at room temperature of $25^{\circ} \mathrm{C}$ for seven days. Mycelia growth was assessed by measuring the zone of inhibition (mm).

\section{Antioxidant activity assessment}

The antioxidant activity of $T$. baccata essential oil was evaluated using the DPPH method described by Gülçin et al. (2012). $400 \mu \mathrm{L}$ of the essential oil is mixed with $400 \mu \mathrm{L}$ of methanol at different concentrations $(1 / 1 ; 1 / 2 ; 1 / 4 ; 1 / 8$; $1 / 16 ; 1 / 32$ and 1/64). From each concentration, $100 \mu \mathrm{L}$ of the mixture (methanol- essential oil) was incorporated with $2900 \mu \mathrm{l}$ of methanolic solution of DPPH (4 mg / $100 \mathrm{~mL}$ of methanol equivalent to $0.004 \%$ ). After vortexing, the mixture was left in the dark for $30 \mathrm{~min}$ at room temperature then the absorbance was measured using a spectrophotometer at $517 \mathrm{~nm}$. DPPH was used as a negative control and BHT (Butylate Hydroxy Toluene) as a positive control. All the tests were carried out in triplicate. The antioxidant activity is estimated in percentage, according to the following formula:

$$
\text { Antioxydant Activity }(\%)=\frac{\text { Abs negative control }- \text { Abs sample }}{\text { Abs negative control }} \times 100
$$

\section{Statistical analysis}

All data were expressed as means \pm standard deviation of triplicate measurements. The significant results of biological activities were analyzed by ANOVA two-way using a CoStat v 6.4 software package. Differences with P $<0.05$ were considered significant.

\section{RESULTS AND DISCUSSION}

\section{Chemical composition}

The hydro distillation of the aerial parts (leaves and stems) of Taxus baccata has given a yellow liquid. The essential oil yield was $0.06 \%$. The essential oil composition analysis was carried out by gas chromatography coupled with mass spectrometry (GC-MS). The analysis of the essential oil has allowed to identify 27 compounds representing $98 \%$ of the total oil. The components identified and their relative abundances are listed in Table 1. Undecanone- 2 with a rate of $76.96 \%$ represents the major component of $T$. baccata essential oil, followed by nonanone-2 $(7.57 \%)$, tridecanone-2 $(4.43 \%)$, decanone-2 $(3.92 \%)$ and methyl dehydroabietate $(1.91 \%)$. T. baccata essential oil is very rich in ketone $(90.97 \%)$, on the other hand the remaining chemical classes are represented in small percentage ranging from 0.18 to $2.66 \%$ in the essential oil.

\section{Antibacterial activity}

The antibacterial activity is estimated by measuring the diameters of inhibition of the bacterial strains (Table 2). Antibacterial test of $T$. baccata essential oil against several bacterial species have shown that $P$. aeruginosa, B. cereus, $P$. mirabilis, E. coli and $S$. aureus, are sensitive to the essential oil. The bacterial strain MRSA was the most resistant to $T$. baccata oil with an average inhibition diameter of $8.33 \pm 0.57 \mathrm{~mm}$, in contrast $P$. aeruginosa was the most sensitive with an average inhibition diameter of $15.33 \pm 0.5 \mathrm{~mm}$. The pure essential oil was the most effective against $E$. faecalis, $S$. aureus, $E$. coli, $P$. aeruginosa and $B$. cereus. The essential oil diluted to $1 / 2$ was more effective than pure oil in inhibiting the growth of B. cereus, with an average diameter of inhibition of $14.66 \pm$ $0.6 \mathrm{~mm}$. The essential oil diluted to $1 / 3 \mathrm{did}$ not affect the strains tested. 
Table 1. Chemical composition of Taxus baccata essential oil from Babor, Algeria

\begin{tabular}{|c|c|c|c|}
\hline Components & $\underset{(\mathbf{m i n})}{\mathbf{R T}}$ & $\begin{array}{l}\text { Kovats } \\
\text { retention } \\
\text { index }\end{array}$ & $\%$ \\
\hline Isopropyl-2-methyl butyrate & 5.091 & 883 & 0.03 \\
\hline Heptanone-2 & 5.175 & 987 & 0.05 \\
\hline$\alpha$-pinene & 6.168 & 933 & 1.13 \\
\hline Benzaldehyde & 6.876 & 964 & 0.03 \\
\hline Sabinene & 7.085 & 973 & 0.37 \\
\hline$\beta$-pinene & 7.192 & 1077 & 0.07 \\
\hline Octanone-2 & 7.490 & 1190 & 0.05 \\
\hline$\Delta 2$-carene & 8.082 & 1117 & 0.03 \\
\hline Limonene & 8.354 & 1230 & 0.29 \\
\hline$\beta$-phellandrene & 8.385 & 1231 & 0.05 \\
\hline$\beta$-ocimene-(E) & 8.728 & 1247 & 0.03 \\
\hline$\gamma$-terpinene & 8.982 & 1259 & 0.04 \\
\hline Nonanone-2 & 9.699 & 1292 & 5.57 \\
\hline Linalool & 8.863 & 1299 & 0.07 \\
\hline Sabinene hydrate-trans & 9.908 & 1202 & 0.07 \\
\hline n-nonanal & 9.970 & 1205 & 0.15 \\
\hline Mentha-2,8-dien-1-ol & 10.322 & 1323 & 0.01 \\
\hline Terpinen-4-ol & 11.484 & 1382 & 1.11 \\
\hline Decanone-2 & 11.689 & 1393 & 3.92 \\
\hline Myrtenol & 13.274 & 1380 & 0.57 \\
\hline Undecanone-2 & 13.795 & 1310 & 76.96 \\
\hline Tridecanone-2 & 13.821 & 1311 & 4.43 \\
\hline$\gamma$-undeca lactone & 18.171 & 1383 & 0.29 \\
\hline Caryophyllene oxide & 18.242 & 1388 & 0.65 \\
\hline Humulene-14-hydroxy & 18.429 & 1301 & 0.09 \\
\hline Bergaptene-iso & 24.101 & 1434 & 0.03 \\
\hline Methyl dehydro-abietate & 25.741 & 1476 & 1.91 \\
\hline \multicolumn{4}{|l|}{ Chemical classes (\%) } \\
\hline Hydrocarbon monoterpenes & & & 2.66 \\
\hline Hydrocarbon sesquiterpenes & & & 0.75 \\
\hline Ketones & & & 90.97 \\
\hline Aldehyde & & & 0.18 \\
\hline Ester & & & 1.94 \\
\hline Alcohol & & & 1.18 \\
\hline Other & & & 0.32 \\
\hline
\end{tabular}

Table 3. Main effects and interactions of essential oils of Taxus baccata

\begin{tabular}{lccc}
\hline \multicolumn{1}{c}{ Source } & Df & F & P \\
\hline Main effects & & & \\
Doses & 6 & 66.459997 & $.0000 * * *$ \\
Bacteria & 6 & 705.28952 & $.0000 * * *$ \\
Interaction & & & \\
Doses * Bacteria & 36 & 257.03619 & $.0000 * * *$ \\
\hline
\end{tabular}

The diameter of inhibition of $\mathrm{T}$. baccata pure essential oil was greater than that of the antibiotics colestin sulfate and imipenem, on the other hand, the action of this oil is less than the action of the two antibiotics Cefotaxime and Gentamicin, which are classified in the group "a" (Figure 2.A). The essential oil dilution with $1 / 3$ showed the lowest activity with an inhibition diameter of $3.83 \mathrm{~mm}$; statistically these results are significant in inhibiting the growth of bacteria. The study of the sensitivity of the bacteria to the essential oil of $T$. baccata showed that $S$. aureus, classified in the group "a", is the most sensitive with an average diameter of inhibition of $15.67 \mathrm{~mm}$ (Figure 2.B). On the other hand, the MRSA bacteria classified in the category " $\mathrm{f}$ " is the most resistant to essential oil with an average diameter of inhibition of $7.71 \mathrm{~mm}$.

The desirability profile of the essential oil of T. baccata against the bacteria tested had a predictive value of 0.47323 (Figure 3). The value of the essential oil is low (less than the predicted value) with the exception of pure essential oil, which indicates a value very close to the predicted value. The essential oil dilutions (1/2 and 1/3) have low activity against the bacteria tested. Desirability test shows that the bacterial strains used in this study are not sensitive to the essential oil of T. baccata.

\section{Antifungal activity}

The disk diffusion method has allowed evaluating the antifungal activity of the essential oil of T. baccata against four phytopathogenic fungal strains (Table 4). Pure essential oil was the most effective against the four fungal strains tested. With an inhibition diameter of $15.07 \pm 1.75$ $\mathrm{mm}$, Puccinia sp. is the most sensitive to essential oil, whereas the fungi Fusarium oxysporum, Alternaria alternata and Fusarium graminum are less sensitive.

Statistical analysis shows that the effects of doses and fungi as well as their interactions are highly significant $(\mathrm{P}<$ 0.001) (Table 5).

Pure essential oil of $T$. baccata showed the highest effect relative to its dilutions, with a diameter of $13.60 \mathrm{~mm}$. On the other hand, its action on the fungi tested is weak than the negative control (Figure 4.A. The effect of $T$. baccata essential oil on the growth of the fungi tested show that Fusarium oxysporum and Puccinia sp., with inhibition diameters of $12.77 \mathrm{~mm}$ and $12.57 \mathrm{~mm}$, are the most sensitive, these two fungi are classified in group "a". While Fusarium graminum classed in the group "c", with an inhibition diameter of $10,28 \mathrm{~mm}$ (Figure 4.B), was the most resistant to essential oil.

Table 2. Inhibition diameter (mm) of Taxus baccata essential oil

\begin{tabular}{lccccccc}
\hline \multicolumn{1}{c}{ Dilution } & $\boldsymbol{E . c o l i}$ & S. aureus & E. faecalis & P. aeruginosa & P. mirabilis & B. cereus & MRSA \\
\hline 1 & $10.3 \pm 0.6$ & $11.3 \pm 0.6$ & $10.3 \pm 0.6$ & $15.3 \pm 0.6$ & $11.3 \pm 1.2$ & $11.7 \pm 0.6$ & 0 \\
$1 / 2$ & $7.7 \pm 0.6$ & $8.7 \pm 0.6$ & 0 & $10.3 \pm 0.6$ & $8.7 \pm 0.6$ & $14.7 \pm 0.6$ & $8.3 \pm 0.6$ \\
$1 / 3$ & 0 & $8 \pm 0$ & 0 & $7.7 \pm 0.57$ & 0 & 0 & $8 \pm 0$ \\
Colistin & $15.7 \pm 0.6$ & $17.3 \pm 0.6$ & $6.3 \pm 0.6$ & $14.3 \pm 0.6$ & 0 & $10.3 \pm 0.6$ & 0 \\
Gentamicine & $31.7 \pm 0.6$ & $29.3 \pm 0.6$ & $19.7 \pm 0.6$ & $24.5 \pm 0.5$ & $29.3 \pm 0.6$ & $24 \pm 1$ & $17.3 \pm 0.6$ \\
Cefotaxim & $29.7 \pm 0.6$ & $35 \pm 1$ & $12.7 \pm 0.6$ & $29.7 \pm 0.6$ & $30 \pm 1$ & $29.3 \pm 0.6$ & $20.3 \pm 0.6$ \\
Imipinem & $9.3 \pm 0.6$ & 0 & $9.7 \pm 0.6$ & 0 & $9.7 \pm 0.6$ & 0 & 0 \\
\hline
\end{tabular}

Note: Statistical analysis showed that the dose and bacteria effects are highly significant $(\mathrm{P}<0.001)$ (Table 3 ) 
Table 4. Inhibition diameters ( $\mathrm{mm}$ ) of Taxus baccata essential oil antifungal activity

\begin{tabular}{ccccc}
\hline Dilution & Alternaria alternata & Fusarium graminum & Puccinia sp. & Fusarium oxysporum \\
\hline 1 & $13.14 \pm 1.68$ & $12.14 \pm 0.77$ & $15.07 \pm 1.75$ & $14.05 \pm 1.25$ \\
$1 / 2$ & $10.57 \pm 1.05$ & $8.5 \pm 0.83$ & $10.52 \pm 0.85$ & $11.5 \pm 0.83$ \\
$1 / 3$ & $8.45 \pm 0.79$ & $7.58 \pm 0.42$ & $8 \pm 0.58$ & $9.24 \pm 0.63$ \\
Negative control & $36.66 \pm 1.25$ & $28.66 \pm 1.25$ & $41.33 \pm 1.25$ & $37.33 \pm 0.47$ \\
\hline
\end{tabular}

Table 5. Main effects and interactions of Taxus baccata essential oil in antifungal activity

\begin{tabular}{lccc}
\hline \multicolumn{1}{c}{ Source } & df & F & P \\
\hline Main effects & & & \\
Doses & 3 & 2484.88 & $.0000^{* * *}$ \\
Fungal strains & 3 & 115.89 & $.0000^{* * *}$ \\
& & & \\
Interaction & & 22.69 & $.0000^{* * *}$ \\
Doses * fungs & 9 & \\
\hline
\end{tabular}

The desirability profile of the essential oil of $T$. baccata against the fungal strains tested shows a predictive value of 0.33673 (Figure 5). The pure essential oil and the oil diluted to $1 / 2$ have an important activity on the tested fungus. They have presented a greater value more than the predicted value. However, the 1/3 dose of the essential oil has shown an equal value to the prediction value. The desirability test shows that the fungal strains tested have values greater or equal to the predicted value, except for Fusarium graminum, which has presented a value under 0.33673 .

\section{Antioxidant activity}

The antioxidant activity of $T$. baccata essential oil is evaluated in vitro by the DPPH radical scavenging test. BHT was used as a reference antioxidant to estimate the antioxidant capacity of essential oil (Table 6). The essential oil of $T$. baccata exhibits low antioxidant activity. The antioxidant activity of the essential oil of T. baccata is less effective compared to the antioxidant activity of BHT. The highest percentage of inhibition is observed with pure oil with an average of $35.18 \pm 0.44$, however, the weakest antioxidant activity was noticed on the 1/64 dilution.

The essential oil of $T$. baccata exhibits low antioxidant activity compared to the positive control BHT. T. baccata essential oil with its various dilutions has shown an effect on DPPH (Table 7). The antioxidant activity varies according to the variation of the dilutions used; the percentage of inhibition decreases with the dilution. The most significant inhibition was detected at the $1 / 1$ dilution.
The desirability profile of the essential oil's antioxidant activity has a low prediction value of 0.25764 (Figure 6). The undiluted essential oil has shown values above the prediction value, while the diluted concentrations showed a value close to the prediction value. The positive control BHT has marked a higher value more than the essential oil and the predicted value. The desirability test shows that the different concentrations of essential oil do not have effective antioxidant activity compared to BHT.

\section{Discussion}

The Algerian population of T. baccata from the Babor region is rich in ketone, with high concentrations of undecanone-2 (76.96\%), nonanone-2 (5.57\%), tridecanone-2 (4.43\%) and decanone-2 (3.92\%). $T$. baccata chemical composition is very different from the composition of the same species studied elsewhere. The populations of Turkey present as major components 1octene-3-ol, caryophyllene oxide, and hexahydro farnesyl acetone (Yasar 2013)

In Serbia, the essential oil of $T$. baccata is rich in 1octene-3-ol, (3Z) -hex-3-en-1-ol and myrtenol (Stefanovic et al. 2016). Another study carried out in Serbia by Radulovic et al. (2011) showed that the essential oil of T. baccata exhibits high concentrations of hexahydrofarnesyl acetone, myrenol, (Z) -3-hexenol, senecioic acid and tricosane.

Table 7. Effect of dilutions of Taxus baccata essential oil on antioxidant activity

\begin{tabular}{cccccc}
\hline Rank & Name & Percentage & n & $\begin{array}{c}\text { Significant } \\
\text { groups }\end{array}$ \\
\hline 1 & BHT & 63.99 & 21 & $\mathrm{a}$ & \\
2 & $1 / 1$ & 35.18 & 3 & & $\mathrm{~b}$ \\
3 & $1 / 2$ & 21.76 & 3 & $\mathrm{~b}$ \\
4 & $1 / 4$ & 16.07 & 3 & $\mathrm{~b}$ \\
5 & $1 / 8$ & 11.64 & 3 & $\mathrm{~b}$ \\
6 & $1 / 16$ & 9.50 & 3 & $\mathrm{~b}$ \\
7 & $1 / 32$ & 8.31 & 3 & $\mathrm{~b}$ \\
8 & $1 / 64$ & 7.07 & 3 & $\mathrm{~b}$ \\
\hline
\end{tabular}

Note: LSD $0.05=33.3743779467$

Table 6. Percent inhibition of essential oil of Taxus baccata and BHT

\begin{tabular}{|c|c|c|c|c|c|c|c|c|}
\hline \multicolumn{2}{|c|}{ Dilutions (mg/mL) } & $1 / 1$ & $1 / 2$ & $1 / 4$ & $1 / 8$ & $1 / 16$ & $1 / 32$ & $1 / 64$ \\
\hline Percent & Essential oil & $35.18 \pm 0.4$ & $21.76 \pm 0.2$ & $16.07 \pm 0.6$ & $11.64 \pm 0.4$ & $9.50 \pm 0.2$ & $8.31 \pm 0.4$ & $7.1 \pm 0.3$ \\
\hline Inhibition & BHT & $91.32 \pm 0.4$ & $89.97 \pm 0.3$ & $86.87 \pm 0.2$ & $74.04 \pm 2.2$ & $47.3 \pm 1.9$ & $37.48 \pm 1.2$ & $23.1 \pm 0.7$ \\
\hline
\end{tabular}


The populations of Serbia studied by Stefanović et al. (2016) and those from Turkey studied by Yasar (2013) are dominated by alcohol; while the population of Serbia studied by Radulovic et al. (2011) was found, dominated by monoterpenoids. A recent study on T. baccata red arils in Poland showed that alcohols, ketones, esters and aldehydes are dominated in their volatile profile (Tabaszewska et al. 2021). The intra-specific difference of the chemical composition can be justified by the diversity of environmental and geographic parameters as well by the harvest period (Aboukhalid et al. 2017; Yeddes et al. 2018).

The results of the antibacterial test are consistent with the study by Prakash et al. (2018) which showed that the methanolic extract of $T$. baccata leaves has significant antibacterial activity against gram-positive bacteria. The study by Bernaitis et al. (2013) confirms that methanolic extracts of $T$. baccata have antibacterial activity against multidrug-resistant bacterial strains. Fazeli-Nasab et al.
(2021) has classified the bacteria $B$. cereus as moderately sensitive to plant extract of T. baccata.

Few studies on the antifungal activity of the essential oil of $T$. baccata have been carried out. Diwan et al. (2013) has shown that ethanolic extracts of $T$. baccata exhibit moderate antifungal activity against Candida species from clinical origin. A similar study has found that the extract of $T$. baccata leaves is very active against Candida albicans and Aspergillus niger (Kumar et al. 2006). Methanolic extracts from the leaves of $T$. baccata in Iran showed high efficacy against Candida albicans (Fazeli-Nasab et al. 2021). A study on the bioactive compounds contained in the arils of T. baccata has shown that taxol and taxinine may be responsible for the antifungal activity of $T$. baccata (Siegle and Pietsch. 2018). Nisar et al. (2008) in a study on the antifungal activity have found that Trichophyton longifusus, Microsporum canis and Fusarium solani are sensitive to methanolic extracts of aerial parts of $T$. wallichiana.
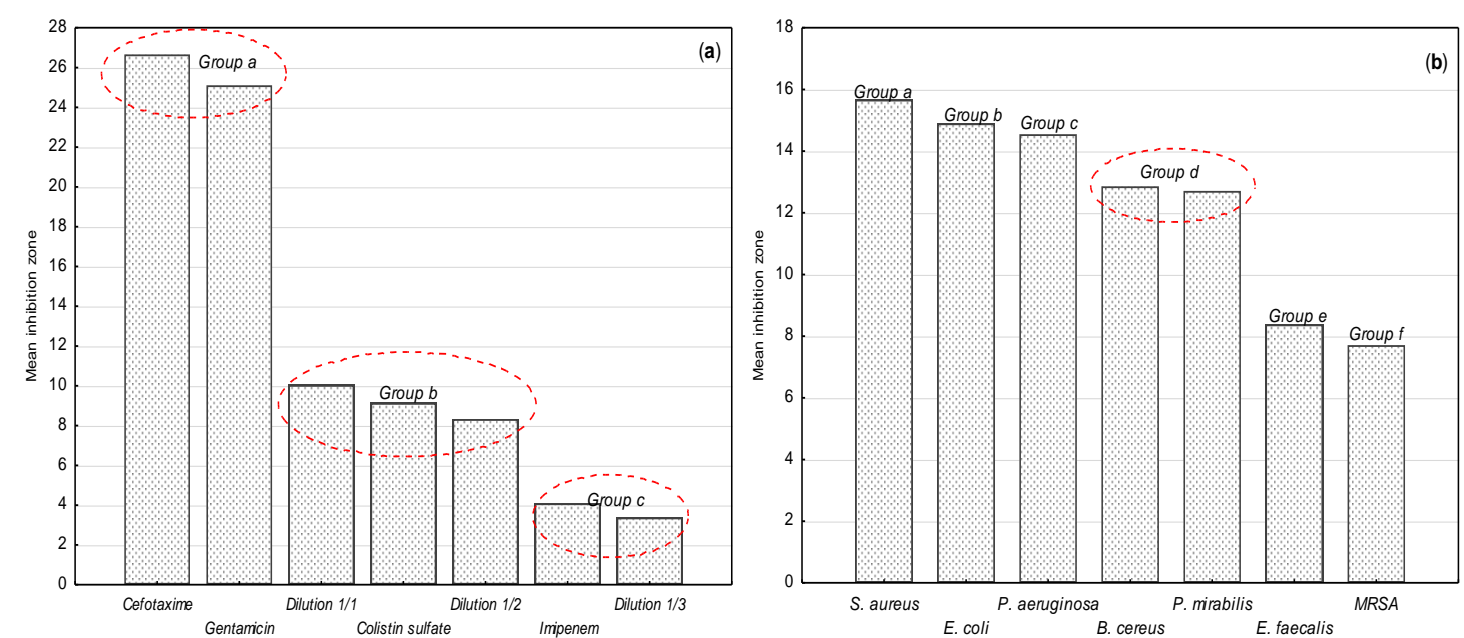

Figure 2. Effect of Taxus baccata essential oil on the bacteria tested. A. Effect of oil dilutions; B. Susceptibility group of bacteria)
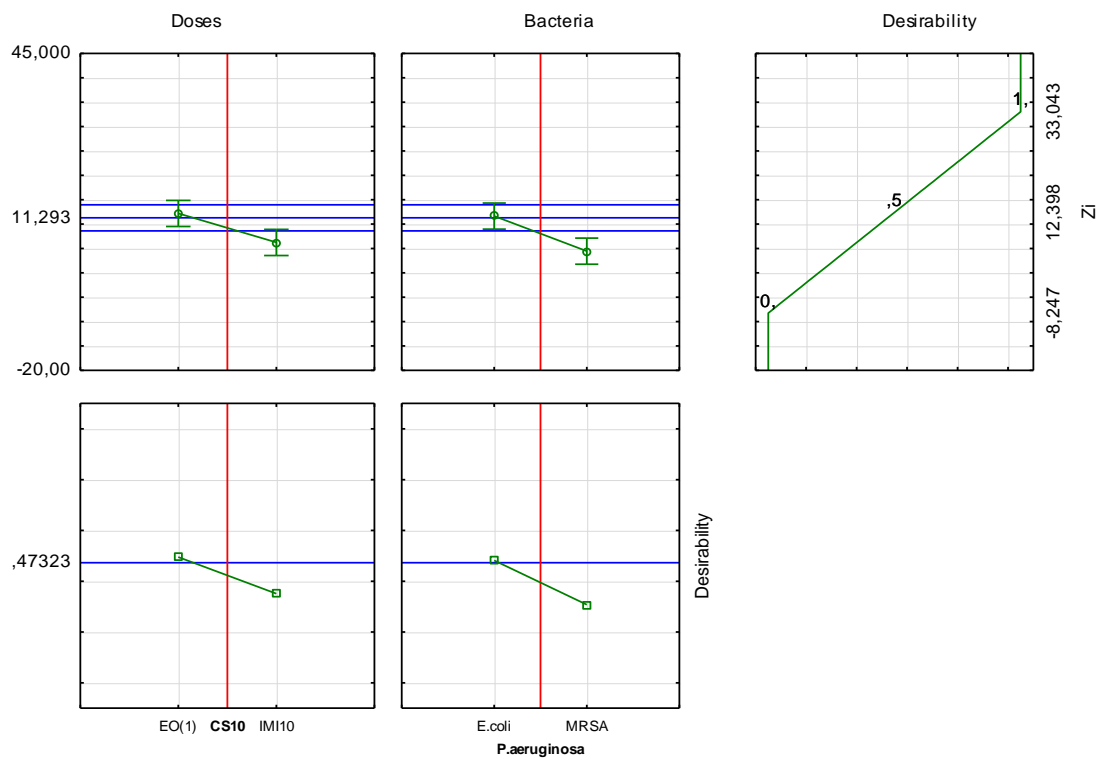

Figure 3. Profile of predicted values and desirability for the inhibition zones induced by Taxus baccata essential oils against bacteria 

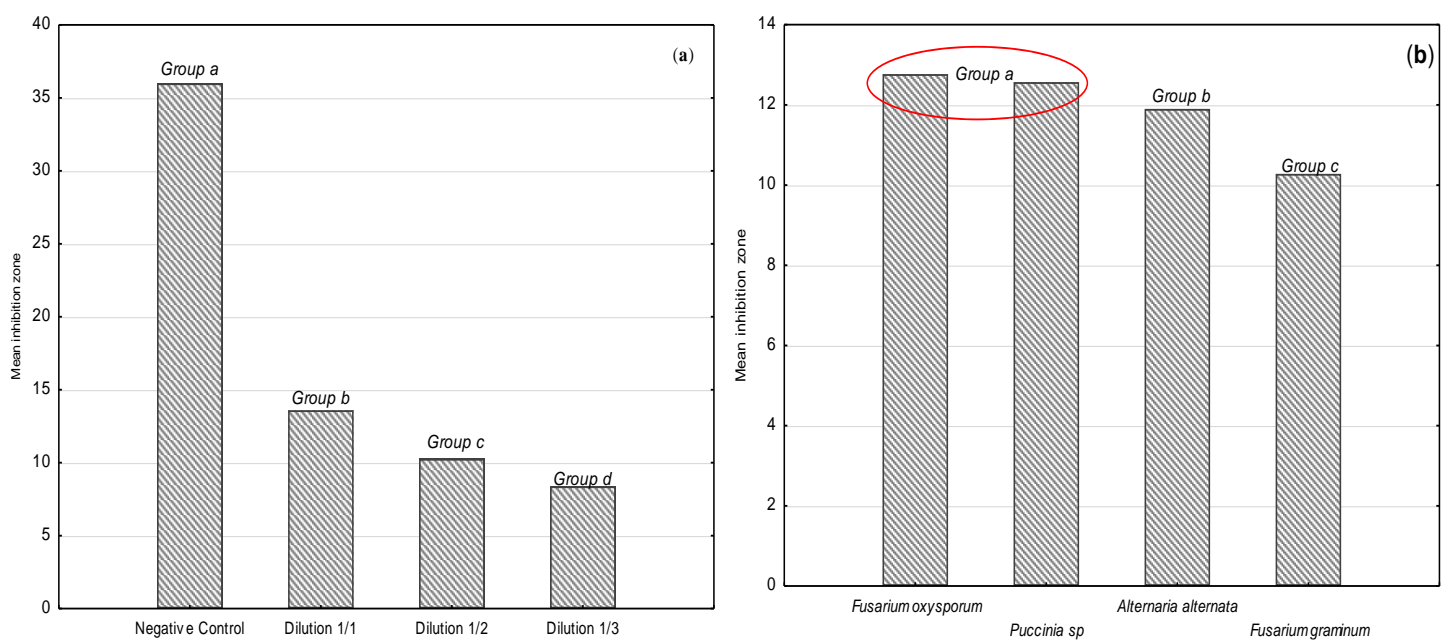

Figure 4. Effect of Taxus baccata essential oil on the fungi tested: A. Effect of oil dilutions; B. susceptibility group of fungi)
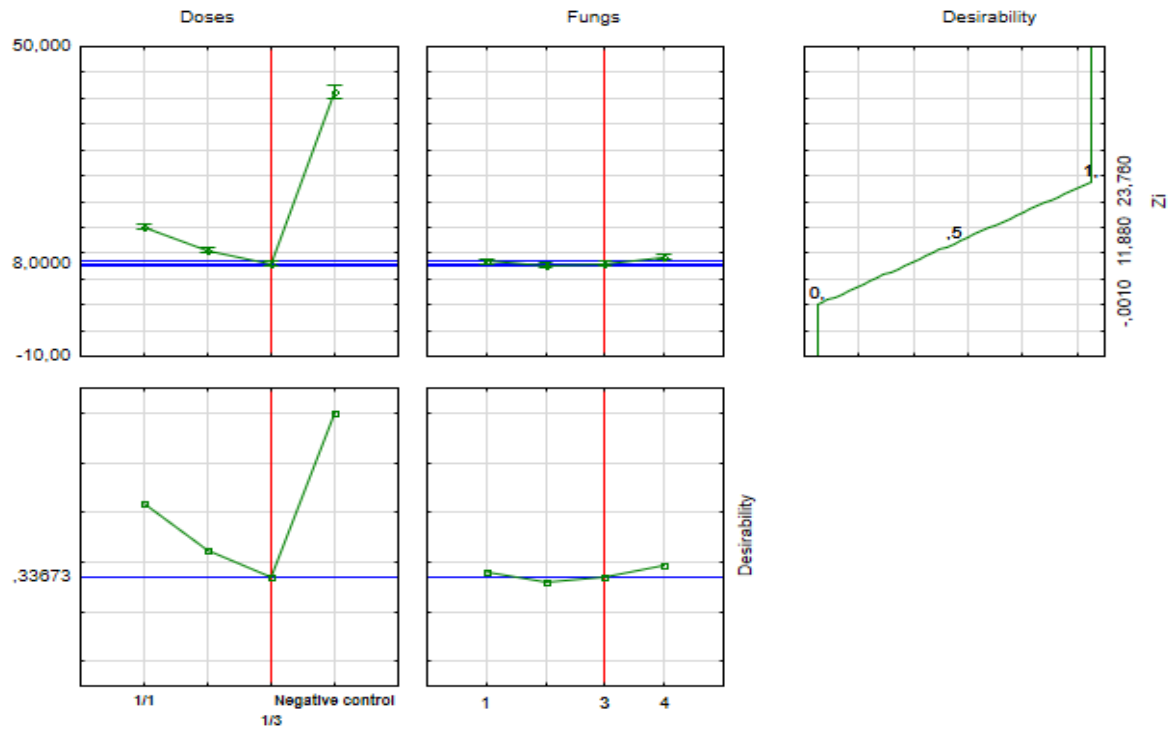

Figure 5. Profile of predicted values and desirability of essential oil of Taxus baccata
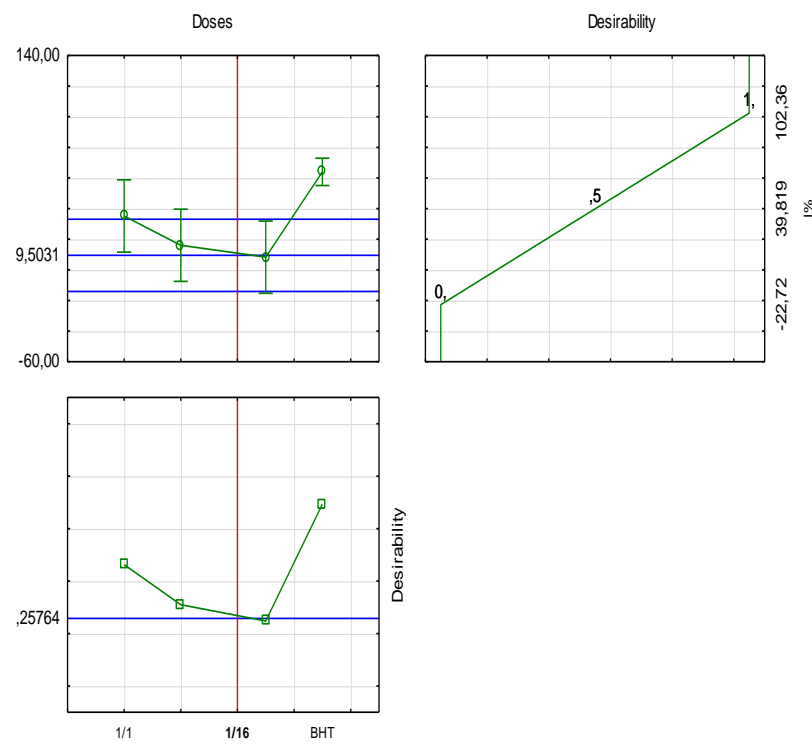

Figure 6. Desirability profile of the antioxidant activity of Taxus baccata essential oil
The essential oil of T. baccata from the Babor region exhibited a low antioxidant activity with an average IC50 of $56.50 \pm 2.78 \mathrm{mg} / \mathrm{mL}$. Senol et al. (2015) showed that T. baccata shoot extract exhibits potential antioxidant activity due to its richness in phenolic compounds. The methanolic extracts of leaves of T. baccata, showed strong antioxidant activity, greater than aqueous and acetone extracts (Prakash et al. 2018). The antioxidant test of methanolic extracts obtained from T. baccata in Serbia shows that the plant has significant DPPH scavenging activity (Milutinović et al. 2015). A study on the bioactive compounds found in red arils of T. baccata, shows that they have an important antioxidant capacity to scavenge DPPH (Tabaszewska et al. 2021). Taxus baccata can be considered as a source of natural antioxidants due to its strong antioxidant capacity (Guleria et al. 2013).

In conclusion, the Taxus baccata essential oil collected from the Babor region in Algeria has a significant yield of $0.6 \%$. GC-GC / MS analysis led to the identification of 27 components in the essential oil, of which undecanone- 2 is 
the major component. The chemical composition of the essential oil of T. baccata in Algeria is different from the chemical composition described in the literature. $T$. baccata essential oil has showed a moderate antibacterial and antifungal activity against the bacterial and the phytopathogenic fungal strains tested. The strains $E$, faecalis, MRSA and Fusarium graminum were resistant to the oil. Taxus baccata essential oil has a moderate antioxidant activity compared to the positive control BHT.

\section{ACKNOWLEDGEMENTS}

This study was supported financially by MESRS of Algeria (Project code No. D01N01UN190120200005); and no potential conflicts of interest.

\section{REFERENCES}

Aboukhalid K, Al Faiz C, Douaik A, Bakha M, Kursa K, Agacka M, Machon N, Tomi F, Lamiri A. 2017. Influence of environmental factors on essential oil variability in Origanum compactum Benth. growing wild in Morocco. Chem Biodivers 14 (9): e1700158. DOI: $10.1002 / \mathrm{cbdv} .201700158$.

Adams RP. 2007. Identification of essential oils components by gas chromatography-mass spectroscopy. Allured Publishing Corporation Carol Stream, IL, USA.

Bajpai VK, Baek KH. 2016. Characterization of microwave extracted essential oil from Taxus cuspidata stem and determination of its phenolic content, antioxidant and free radical scavenging activities. J Essent Oil Bearing Plants (5) 19: 1051-1065. DOI: 10.1080/0972060X.2016.1194234.

Bajpai VK, Sharma A, Moon B, Baek KH. 2013. Antibacterial mode of action of Taxus cuspidata leaf essential oil against food borne pathogens. J Food Safety 34: 9-20. DOI: 10.1111/jfs.12089.

Bekhouche M, Morsli A, Slaoui MK, Benyammi R, Krimat S, Khelifi L. 2021. Free radical scavenging activity and detailed flavonoid profiling of Algerian yew. Intl J Pharm Sci Res 12 (5): 2613-2619. DOI: 10.13040/IJPSR.0975-8232.12(5).2613-19.

Bernaitis L, Shobha KL, Ashok M, Shenoy RP, Mathew J, Khan DM. 2013. Comparative evaluation of the antimicrobial activity of ethanol extract of Taxus baccata, Phyllanthus debilis, Plectranthus amboinicus against multi drug resistant bacteria. Intl J Pharm Sci Res 4 (8): 3147-3150. DOI: 10.13040/IJPSR. 0975-8232.4(8).3147-50.

Dizdarević IM, Žilić D, Dukić B. 2019. New insights into the antifungal activity of Taxus baccata L. Genet Appl 3 (1): 65-70. DOI: 10.31383/ga.vol3iss1 pp65-70.

Fazeli-Nasab B, Rahmani AF, Valizadeh M, Khajeh H, Beigomi M. 2021 Evaluation of antimicrobial activity of some medicinal plants on human standard bacteria and Candida albicans. Gene Cell Tissue 8 (3): e113092. DOI: $10.5812 /$ gct.113092.

Fazeli-Nasab B, Shahraki-Mojahed L, Hassanzadeh MA, Bidarnamani F. 2021. Investigation of antimicrobial activity of medicinal plant extracts on Bacillus cereus isolated from soil. Gene Cell Tissue 9 (1): e115133. DOI: $10.5812 /$ gct.115133.

Fenjuan S, Iain W, Deyou Q. 2021. The research progress of taxol in Taxus. Curr Pharm Biotechnol 22 (3): 360-366. DOI: 10.2174/1389201021666200621163333.

Ganie SA, Ahmad M, Yaseen M, Bhat A, Ganai BA, Zargar MA, Qureshi R. 2015. Taxus wallichiana as a potential in vitro Antioxidant with good lethal effect on pathogenic bacterial strains. Am J Phytomed Clin Therapeutic 3 (3): 209-221.

Gülçin I, Elmastas M, Aboul-Enein HY. 2012. Antioxidant activity of clove oil - A powerful antioxidant source. Arabian J. Chem 5 (4) 489-499. DOI: 10.1016/j.arabjc.2010.09.016.

Guleria S, Tiku AK, Singh G, Koul A, Gupta S, Rana S. 2013. In vitro antioxidant activity and phenolic contents in methanol extracts from medicinal plants. J Plant Biochem Biotechnol 22: 9-15. DOI: $10.1007 / \mathrm{s} 13562-012-0105-6$
Huong LT, Nguyen TH, Chac LD, Dai DN, Ogunwande A. 2020. Antimicrobial activity and chemical constituents of essential oils from the leaf and wood of Taxus chinensis (Rehder \& E.H. Wilson) Rehder (Taxaceae) from Vietnam. J Biol Active Prod Nat 10 (1): 8-17. DOI: 10.1080/22311866.2020.1749128.

Jian-Chun X, Li-Huang L, Hui-Ying Z, Hui-Lan H, Bao-Guo S. 2012. Volatile constituents of Taxus wallichiana var. Mairei leaves. J Essent Oil Bearing Plants 15 (5): 724-730. DOI: 10.1080/0972060X.2012.10644112.

Jiang S, Zhang Y, Zu Y, Wang Z, and Fu Y. 2011. Antitumor activities of extracts and compounds from water decoctions of Taxus cuspidata. Am J Chin Med 38 (6): 1107-1114. DOI: 10.1142/S0192415X10008500

Khan DM, Bernaitis L, Shobha KL, Ashok M, Revathi Shenoy P. 2013. Antifungal activity of Taxus baccata, Phyllanthus debilis, Plectranthus amboinicus against candida species of clinical origin. Intl J Biol Pharm Res 4 (5): 386-389.

Kumar VP, Chauhan NS, Harish P, Rajani, M. 2006. Search for antibacterial and antifungal agents from selected Indian medicinal $\begin{array}{llll}\text { plants. J Ethnopharmacol } 107 & \text { (2):182-188. DOI: }\end{array}$ 10.1016/j.jep.2006.03.013.

Liu HS, Gao YH, Liu LH, Liu W, Shi QW, Dong M, Suzuki T, Kiyota H. 2016. Inhibitory effect of 13 taxane diterpenoids from Chinese yew (Taxus chinensis) on the proliferation of HeLa cervical cancer cells. Biosci Biotechnol Biochem 80 (10): 1883-1886. DOI: 10.1080/09168451.2016.1194182

Milutinović MG, Stanković MS, Cvetković DM, Topuzović MD, Mihailović VB, Snežana SD. 2015. Antioidant and anticancer properties of leaves and seed cones from European yew (Taxus baccata). Archive Biol Sci 67 (2): 525-534. DOI: 10.2298/ABS141006015M.

Nisar M, Khan I, Ahmad B, Ali I, Ahmad W, Choudhary MI. 2008. Antifungal and antibacterial activities of Taxus wallichiana Zucc. J Enzyme Inhibition Med Chem 23 (2): 256-260. DOI: 10.1080/14756360701505336.

NIST. 2002. Mass Spectral Search Program for the NIST/EPA/NIH Mass Spectral Library, vers. 2.0. fiveash data, USA.

Ponce AG, Fritz R, Del Valle C, Roura SI. 2003. Antimicrobial activity of essential oils on the native microflora of organic Swiss chard. Lebensmittel-Wissenschaft und Technologie 36 (7): 679-684. DOI: 10.1016/S0023-6438 (03)00088-4.

Prakash V, Rana S, Sagar A. 2018. Analysis of antibacterial and antioxidant activity of Taxus baccata Linn. J Med Plants Stud 6 (5): 40-44.

Quézel P, Santa S. 1962. Nouvelle Flore de l'Algérie et des régions désertiques Méridionales. C.N.R.S, Paris.

Radulović N, Blagojević P, Palić R, Zlatković B. 2011. Chemical composition of the essential oil hydrodistilled from Serbian Taxus baccata L. J Essent Oil Res 22 (5): 458-461. DOI: 10.1080/10412905.2010.9700371

Senol FS, Orhan I.E, Ustun O. 2015. In vitro cholinesterase inhibitory and antioxidant effect of selected coniferous tree species. Asian Pac J Trop Med 8 (4): 269-275. DOI: 10.1016/S1995-7645(14)60329-1.

Siegle L, Pietsch J. 2018. Taxus ingredients in the red arils of Taxus baccata L. determined by HPLC-MS/MS. Phytochem Anal 29 (5): 446-451. DOI: 10.1002/pca.2748.

Stefanović M, Ristić M, Popović Z, Matić R, Nikolić B, Vidaković V, Obratov-Petković D, Bojović S. 2016. Chemical composition and interpopulation variability of essential oils of Taxus baccata L. from Serbia. Chem Biodiver 13 (7): 943-953. DOI: 10.1002/cbdv.201500326.

Tabaszewska M, Antoniewska A, Rutkowska J, Skoczylas Ł, Słupski J, Skoczeń-Słupska R. 2021. Bioactive components, volatile profile and in vitro antioxidative properties of Taxus baccata L. red arils. Molecules 26 (15): 4474. DOI: 10.3390/molecules26154474.

Tachibana S, Ishikawa H, Itoh K. 2005. Antifungal activities of compounds isolated from the leaves of Taxus cuspidata var nana against plant pathogenic fungi. J Wood Sci 51: 181-184. DOI: 10.1007/s10086-004-0635-1.

Wahab A, Khera RA, Rehman R, Mushtaq A, Merzaia AB, Azeem MW. 2016. A review on phytochemistry and medicinal uses of Taxus wallichiana L. (Himalayan Yew). Intl J Chem Biochem Sci 9: 116120.

Wei Q, Yin C.W. 2019. Chemical composition of essential oils from the stems of Taxus chinensis var. Mairei. J Essent Oil Bearing Plants 22 (4): 1144-1149. DOI: 10.1080/0972060X.2019.1668864 
Yasar S. 2013. Volatile constituents of Taxus baccata L. leaves from western and southern Turkey. Asian J Chem 25 (16): 9123-9125. DOI: 10.14233/ajchem.2013.15038.

Yeddes W, Wannes W.A, Hammami M, Smida M, Chebbi A, Marzouk B, Tounsi MS. 2018. Effect of environmental conditions on the chemical composition and antioxidant activity of essential oils from Rosmarinus officinalis L. growing wild in Tunisia. J Essent Oil Bearing Plant $21 \quad$ (4): 972-986 10.1080/0972060X.2018.1533433.
Zazharskyi VV, Davydenko PO, Kulishenko OM, Borovik IV, Brygadyrenko VV. 2019. Antimicrobial activity of 50 plant extracts. Biosyst Divers 27 (2): 163-169. DOI: 10.15421/011922.

Zhao CJ, Xin H, Li CY, Lei Y, Yujie F, Kaiting W, Yukun Z, Yujiao N. 2016. A microwave-assisted simultaneous distillation and extraction method for the separation of polysaccharides and essential oil from the leaves of Taxus chinensis var. Mairei. Appl Sci 6 (2): 1-19: DOI: 10.3390/app6020019. 